\title{
The Role of Inflammation in Venous Thromboembolism
}

OPEN ACCESS

Edited by:

Birgit Knoechel,

Dana-Farber Cancer Institute,

United States

Reviewed by:

Cameron C. Trenor

Boston Children's Hospital, Harvard

University, United States

Leo D. Wang

City of Hope National Medical Center,

United States

*Correspondence:

Brian R. Branchford

brian.branchford@

childrenscolorado.org

Specialty section:

This article was submitted to

Pediatric Hematology and Hematological Malignancies,

a section of the journal

Frontiers in Pediatrics

Received: 11 January 2017 Accepted: 27 April 2018 Published: 23 May 2018

Citation:

Branchford BR and Carpenter SL (2018) The Role of Inflammation in Venous Thromboembolism. Front. Pediatr. 6:142. doi: 10.3389/fped.2018.00142

\section{Brian R. Branchford ${ }^{1 *}$ and Shannon L. Carpenter ${ }^{2}$}

${ }^{1}$ University of Colorado Hemophilia and Thrombosis Center, Pediatric Hematology, University of Colorado School of Medicine and Children's Hospital Colorado, Aurora, CO, United States, ${ }^{2}$ Kansas City Regional Hemophilia Treatment Center, Pediatric Hematology, UMKC School of Medicine and Children's Mercy Hospital, Kansas, CO, United States

Venous thromboembolism (VTE), comprising deep vein thrombosis (DVT), and pulmonary embolism (PE), is becoming increasingly recognized as a cause of morbidity and mortality in pediatrics, particularly among hospitalized children. Furthermore, evidence is accumulating that suggests the inflammatory response may be a cause, as well as consequence, of VTE, but current anticoagulation treatment regimens are not designed to inhibit inflammation. In fact, many established clinical VTE risk factors such as surgery, obesity, cystic fibrosis, sepsis, systemic infection, cancer, inflammatory bowel disease, and lupus likely modulate thrombosis through inflammatory mediators. Unlike other traumatic mechanisms of thrombosis involving vascular transection and subsequent exposure of subendothelial collagen and other procoagulant extracellular matrix materials, inflammation of the vessel wall may initiate thrombosis on an intact vein. Activation of endothelial cells, platelets, and leukocytes with subsequent formation of microparticles can trigger the coagulation system through the induction of tissue factor (TF). Identification of biomarkers to evaluate VTE risk could be of great use to the clinician caring for a patient with inflammatory disease to guide decisions regarding the risk:benefit ratio of various types of potential thromboprophylaxis strategies, or suggest a role for anti-inflammatory therapy. Unfortunately, no such validated inflammatory scoring system yet exists, though research in this area is ongoing. Elevation of C-reactive protein, IL-6, $\mathrm{IL}-8$, and TNF-alpha during a response to systemic inflammation have been associated with increased VTE risk. Consequent platelet activation enhances the prothrombotic state, leading to VTE development, particularly in patients with other risk factors, most notably central venous catheters.

Keywords: pediatrics, venous thromboembolism, thrombosis, inflammation, cytokines, platelets, risk factors

Evidence is accumulating that the factors influencing VTE formation are not restricted to the coagulation system alone, but rather that the immune system is also closely involved with formation and resolution of thrombosis. It is important to consider the contributions of inflammation to VTE development in general, but also as it pertains to certain specific disease categories more commonly associated with development of hospital-acquired VTE (HA-VTE) in some patients. Surgery, (13) obesity, (4) cystic fibrosis, (5-7) sepsis, (8-10) systemic infection, $(11,12)$ cancer, $(13-15)$ inflammatory bowel disease, (16-18), and lupus (19-22) are clinical VTE risk factors that may modulate thrombosis through inflammatory mediators. Understanding the role of inflammation in these particular clinical situations may not only help determine the optimal management but may also aid in the development of future preventative strategies, since current anticoagulation treatment regimens are not designed to inhibit inflammation (23). 
Recently, inflammation has been accepted as a common pathway through which various risk factors trigger VTE formation. A feasible mechanism is that inflammation of the vessel wall initiates thrombus formation in an intact vein and that inflammation and coagulation systems are coupled by a common activation pathway. The first event in thrombus formation is probably activation of endothelial cells, platelets, and leukocytes, with initiation of inflammation and formation of microparticles that trigger the coagulation system through the induction of TF. Therefore, the key event in the initiation of VTE formation is most likely vein wall inflammation, but the contribution of specific immune modulators has not yet been elucidated. Recently, it was demonstrated that probable association between VTE and several other markers of inflammation such as Creactive protein (CRP), IL-6, IL-8, and tumor necrosis factoralpha exists (24-28). These pro-inflammatory cytokines play an important role in VTE by promoting a pro-coagulant state primarily by inducing the expression of tissue factor. Several immune system components (cytokines, chemokines, and various leukocyte subtypes) are involved in the underlying inflammatory process of VTE, as is very well-described in a recent review from Saghazadeh et al. (23). Additionally, it has been recently described that inflammatory mediators such as polyphosphates, bradykinin, and others may directly activate the contact system (the polyphosphate-Factor XII association is particularly notable) and initiate the extrinsic coagulation pathway (29-31).

The identification and elucidation of inflammatory markers relevant to VTE could provide targets for future therapy. That inflammation is the basic etiopathogenic process of VTE is also supported by the relation of some risk factors to both arterial and venous thrombosis: age, increased BMI, atherosclerotic disease, hypercholesterolemia, hypertension, antiphospholipid antibodies, and hyperhomocysteinemia (28).

\section{INTERACTION BETWEEN COAGULATION AND INFLAMMATION}

For over a century, thrombosis formation has been attributed to three main groups of factors including alterations in blood flow, endothelial injury, and hypercoagulable state, collectively known as Virchow's Triad (32). A prime example is the frequent association of central venous catheter (CVC) with VTE. Blood flow is altered by the obstacle in the vein, creating turbulent flow in some areas, while promoting stasis in others, depending on local vascular architecture. Additionally, the endothelium is damaged at the catheter insertion site, and the body actively attempts to repair that site with primary and secondary hemostatic efforts. Finally, there is a high likelihood that the underlying disease process that necessitated the need for the CVC in the first place (volume resuscitation in trauma or distributive shock, chemotherapy administration for active cancer, long-term antibiotics for severe infection, etc.) increases the risk for thrombosis. There is also likely a reciprocal relationship between CVC infections leading to increasing risk for line thrombosis and infected clots within a line likely to adversely affect its function. Over the last decade, a growing body of evidence suggests a role for consideration of inflammation as a major contributor to the pathophysiology of VTE, (33) likely by enhancing the hypercoagulable state and increasing endothelial damage. Activation of endothelial cells, platelets, and leukocytes, with subsequent initiation of inflammation and microparticle formation, triggers the coagulation system through induction of TF, primarily that borne by microparticles, which may contribute to the hypercoagulable state in the Triad $(28,34,35)$. Both formation and resolution of thrombosis have been associated with a series of inflammatory cascades $(36,37)$. Moderate to severe degrees of inflammation (inflammatory infiltrates throughout the thrombi, mostly composed of lymphocytes, with some mixing of other components including plasma cells, neutrophils, and eosinophils) (38) were found in approximately $15 \%$ of thrombus specimens from pulmonary thromboendarterectomy (23) and immunity/inflammatory genes constitute nearly $10 \%$ of those genes whose expressions are substantially altered under the influence of $\operatorname{VTE}(38,39)$. A reciprocal relationship exists in which patients with VTE have an increased risk of myocardial infarction and stroke, and vice versa, while proven cardiovascular risk factors such as obesity, tobacco use, diabetes, stress, and diet increase the risk of both atherothrombotic events and VTE, likely due to the common pathophysiological mechanism of promoting cardiovascular inflammation (40).

Evidence of specific pathophysiologic links between the coagulation system and innate immunity continues to mount. Polyphosphate (polyP) is present in human platelet dense granules and is released upon platelet activation, assisting with coagulation by increasing activation of factor $\mathrm{V}$, decreasing tissue factor pathway inhibitor (TFPI) activity, and delaying clot lysis by activating thrombin-activatable fibrinolysis inhibitor (TAFI) (41-44). PolyP is also a potent pro-inflammatory signal when released from mast cells during a hypersensitivity reaction, for example (42).

Additionally, histones have been shown to be increased in sepsis and other inflammatory conditions along with nucleosomes (DNA + histones), and are toxic to the endothelium. Activated protein $\mathrm{C}$ inactivates histones, protecting the endothelium in the process (45). Extracellular DNA fibers extruded from neutrophils (Neutrophil Extracellular Traps, NETs) are produced in response to infection to allow neutrophils to trap and destroy invading microorganisms. Fibrin formation and deposition has been shown to be stimulated by NETs, and fibrin formation is also important in trapping organisms and controlling infection (46). NETs also cause platelet adhesion and have been shown to be linked to deep vein thrombosis in experimental models (47). Moreover, platelets have been shown to stimulate NET production (46). There is also evidence that some bacteria interact with platelets, either directly or through antibody-mediated mechanisms, leading to platelet activation or contributing to thrombus development. Other interactions have been identified which are beyond the scope of this brief review and have been described excellently elsewhere (45, 48-50).

Inflammation can be both a cause and a consequence of VTE, but current anti-coagulation treatment regimens are not 
specifically designed to inhibit inflammation (though it is known that heparins have some anti-inflammatory effects). Selective pharmacologic targeting of immune/inflammatory mediators in VTE may result in more effective therapeutic or prophylactic strategies (23). It is important to note, however, that the role of anti-inflammatory therapies in VTE prevention efforts is still not well-established. One study demonstrated a 2-fold or more increased risk of VTE with the use of non-selective nonsteroidal anti-inflammatory drugs (NSAIDs) or cyclooxygenase2 -selective (COX-2) inhibitors (51). These results were reflected in a recent systematic review and meta-analysis in which the pooled risk ratio among NSAID users was 1.8 -fold for VTE (52). Adequate VTE mechanism data in this setting are not yet available, however, to determine whether the antiinflammatory medication itself drives the VTE formation or whether inflammation drives the usage in patients who are being treated with anti-inflammatory drugs to manage their underlying medical condition. The same question may be considered in users of steroids, though it has been shown more specifically that glucocorticoids increase levels of clotting factors and fibrinogen, which may explain the elevated VTE risk (especially pulmonary embolism) demonstrated in a recent Danish study of glucocorticoid users that followed an associated temporal pattern, persisted after adjustment for underlying disease severity, and existed even in non-inflammatory conditions (53). A similar effect with 1.5-fold increased VTE risk was seen in subjects treated with glucocorticoids for at least 30 days prior to surgery (54).

Particular disease subgroup-specific relationships have been studied, as seen below and in Table 1.

\section{SURGERY AND TRAUMA}

Surgery and trauma are linked in terms of HA-VTE risk due to the tissue injury they have in common. The role of inflammation in driving HA-VTE risk in these clinical situations is primarily related to the process through which transected vessels and tissue undergo physiologic repair. The innate immune system is activated following tissue injury, platelets degranulate locally after recruitment from the circulation, and tissue macrophages and mast cells are activated with a combined effect of leukocyte chemoattraction (55). Neutrophils infiltrate the wound, followed by additional circulating monocytes that differentiate into mature tissue macrophages, (56) and later by additional infiltration of mast cells from adjacent tissue (57), and finally by T-lymphocytes (58). The collective result of these cellular activation processes is increased release of IL-1, IL6, IL-12, and TNF $\alpha(59,60)$. IL-6 has been demonstrated to play a critical role in inflammation-related thrombosis (61) increased concentrations of IL-6, along with TNF $\alpha$ and IL-8 are potent risk predictors for VTE, even after adjustment for covariates, including CRP (62). Additional neutrophil presence (following chemoattractant release from platelets and mast cells) and subsequent NET formation have been linked to venous thrombosis $(47,63)$. The interaction between endothelial Eselectin, leukocyte L-selectin, and platelet P-selectin also plays an important role in platelet-leukocyte aggregation and adherence to vessel walls at sites of surgical or traumatic injury. P-selectin inhibition has been shown to decrease venous thrombosis in murine (64) thrombosis models and enhance thrombus resolution in rat models (65). Similarly, E-selectin inhibition with a small molecule inhibitor has been shown to decrease inflammation (vein wall monocyte extravasation) and acute venous thrombosis in a surgical model of murine thrombosis induction (66) and is now being studied in early clinical trials in humans.

\section{INFLAMMATORY BOWEL DISEASE}

Among VTE-related hospitalizations, the presence of IBD was associated with a 2.5 -fold increased risk of mortality in one population-based study (18). No studies have specifically evaluated the potential benefit of VTE prophylaxis in hospitalized or ambulatory IBD patients, but studies to date do not support an increased bleeding risk with moderate doses of anticoagulant medications in IBD patients with active disease (18). Recent large studies have quantified this risk showing that IBD patients run a 1.5 to 3.6 higher risk of developing VTE than healthy controls $(16,17)$. IBD has been demonstrated to represent an independent risk factor for the recurrence of VTE (17).

IBD has been previously associated with increased levels of TNF $\alpha$ (67) with upregulation of TNF $\alpha$ mRNA in colonic tissue in patients with Crohn's Disease (68) and Ulcerative Colitis (69) and many current therapeutic regimens involve a focus on blocking signaling through this molecule. Giannotta et al. (16) have recently reviewed the specific effects of $\mathrm{TNF} \alpha$ on activation of intrinsic coagulation pathway by inducing tissue factor expression on leukocyte surfaces, downregulation of natural anticoagulants (protein $\mathrm{C}$ and heparinantithrombin pathways) in addition to thrombomodulin and the endothelial protein $\mathrm{C}$ receptor, increasing platelet production and enhancing thrombin formation in conjunction with IL-6, and triggering (in conjunction with IBD-associated elevation in homocysteine) expression of vascular cell adhesion protein1 and monocyte chemoattractant protein 1 on endothelial surfaces leading to enhanced capacity to recruit $\mathrm{T}$ cells and monocytes.

\section{OBESITY}

Obesity is a known risk factor for arterial and venous thrombosis. Studies have shown that obesity conveys an odds ratio of 1.7-2.2 for VTE, similar to that of other known VTE risk factors (70). A recent cohort of 268 adults with incident VTE events over 4.6 years from the Reasons for Geographic And Racial Differences (REGARDS) cohort demonstrated that higher CRP levels and lower serum albumin levels were associated with increased VTE risk and statistically mediated part of the association of body mass index (BMI) with VTE, suggesting that inflammation may be a potential mechanism underlying the relationship between obesity and VTE risk. White blood cell (WBC) count and platelet 
TABLE 1 | Inflammatory considerations in specific clinical situations.

\begin{tabular}{|c|c|}
\hline Clinical subgroup & Inflammatory considerations \\
\hline Surgery & $\begin{array}{l}\text { The healing process is, at baseline, inflammatory since this is the mechanism by which tissues are re-approximated and } \\
\text { cellular debris is cleared. Surgery may also be in response to an inflammatory stimulus (e.g., cancer, abscess, trauma). SCD } \\
\text { usage may be helpful in surgeries extending over a certain time duration because of their mechanism of replacing the } \\
\text { venous return assistance usually provided by the body's lower extremity muscle contractions while walking. }\end{array}$ \\
\hline Inflammatory bowel disease & $\begin{array}{l}\text { Various reports of odds ratio between } 1.5 \text { and } 3.5 \text { for increased VTE risk in patients with IBD. Primary risk factors in this } \\
\text { subgroup include disease severity, colonic localization, and recent surgery. Risk decreases with treatment of underlying } \\
\text { condition. }\end{array}$ \\
\hline Obesity & $\begin{array}{l}\text { Obesity confers an odds ratio between } 1.7 \text { and } 2.2 \text { for VTE, likely acting through higher CRP levels found in subjects with } \\
\text { higher BMI, in addition to potential for decreased physical activity. }\end{array}$ \\
\hline Cystic fibrosis & $\begin{array}{l}\text { Multifactorial increased VTE risk: frequent hospitalizations, systemic or severe local infections (especially with specifically } \\
\text { thrombogenic strains such as B. cepacia), elevated acute phase reactants, CVC presence, activated platelets. Risk } \\
\text { decreases with appropriate management of underlying condition. }\end{array}$ \\
\hline Sepsis/systemic infection & $\begin{array}{l}\text { Specific risk from acute phase reactant release (tissue factor, WWF, procoagulant microparticles), inhibition of fibrinolysis, } \\
\text { NET formation, etc. Risk is increased in both systemic and severe local infections. }\end{array}$ \\
\hline Systemic lupus erythematosus & $\begin{array}{l}\text { Particularly challenging due to existence of both chronic and acute inflammatory-driven risk states and auto-immune } \\
\text { component (APLA, innate immune dysregulation, etc.). Risk decreases with treatment of underlying condition. }\end{array}$ \\
\hline
\end{tabular}

count were not determined to have any relationship. Adipocytes secrete inflammatory cytokines leading to chronic, low-grade inflammation resulting from recruitment of macrophages to adipose tissues that progressively accumulate as fat mass increases, and drive a progression of anti-inflammatory M2 macrophages to proinflammatory M1 macrophages, leading to increased secretion of proinflammatory cytokines including TNF $\alpha$, IL-6, and IL-1 $\beta$, as well as impaired fibrinolysis due to marked increase in plasminogen activator inhibitor-1 expression (70). These proinflammatory cytokines, as well as adipokines such as leptin, stimulate vascular endothelium, platelets, and other circulating vascular cells, leading to upregulation of procoagulant factors including tissue factor and cellular adhesion molecules, downregulation of anticoagulant regulatory proteins, increased thrombin generation, and enhanced platelet activation (71). Finally, aberrant microRNA expression patterns likely contribute to thrombosis in obesity through decreased endothelial nitric oxide bioavailability, unregulated expression of endothelial adhesion molecules, and enhanced platelet activation and degranulation as reviewed by Blokhin and Lentz (72).

\section{CYSTIC FIBROSIS (CF)}

$\mathrm{CF}$ is a multi-system inflammatory disease, complicated by excessive production of thick mucus secretions that lead to pulmonary infectious exacerbations resulting in hospitalization for IV antibiotics, frequently through a CVC. These patients have increased risk of thrombosis due to CVCs, as well as acquired thrombophilia secondary to inflammation [including both the elevation of pro-coagulant acute phase reactant proteins such as fibrinogen, factor VIII, and/or von Willebrand factor (VWF), as well as the suppression of protein $\mathrm{S}$ by inflammation-related $\mathrm{C} 4 \mathrm{~B}$ binding protein], or natural anticoagulant protein deficiencies due to vitamin $K$ deficiency and/or liver dysfunction (6). Also, the incidence of antiphospholipid antibodies that may be associated with increased thrombotic risk ranges from about $5-10 \%$ in patients with $\mathrm{CF}$, which is elevated compared to that reported in healthy children $(1-3 \%)(73,74)$. While platelets are generally thought to play a more significant role in the pathogenesis of arterial thrombosis (coronary heart disease and stroke), it has been postulated that activated platelets may contribute to pulmonary inflammation and tissue destruction in $\mathrm{CF}$, specifically (75). Certain specific pulmonary infections, such as Burkholderia cepacia, may also increase VTE risk in CF patients (76).

VTE in children with cystic fibrosis was recently studied at a single center and the incidence rate was found to be 53 VTE cases per 10,000 children with CF. Several inflammatoryspecific risk factors for VTE were reported, including sinus disease, positive respiratory cultures, and elevated inflammatory markers such as erythrocyte sedimentation rate and CRP (7). A recent retrospective study of 116 adults with CF hospitalized for pulmonary exacerbations using a CVC demonstrated a $2.5 \%$ incidence of catheterrelated VTE (77). Elevated CRP was associated with the thrombosis group but did not reach statistical significance $(p=0.51)$ and the time to VTE development was shorter for peripherally-inserted central catheter (PICC) lines compared to Port-a-Cath, though the only two recurrent events occurred in subjects with Port-a-Caths (77). A prospective study of 90 adult and pediatric CF patients, on the other hand, demonstrated a CVC-related VTE frequency of $6.6 \%$ (combination of symptomatic clots and those detected by screening ultrasound) (5). This study did not identify biomarkers (CRP, D-dimer, fibrinogen) for inflammatory/hypercoagulable screening at the time of catheter insertion, but did emphasize the contribution of VTE history and raises the issue of prospective Doppler ultrasound for consideration in identifying asymptomatic CVC-VTEs, though the role of anticoagulant therapy in the management of these patients remains controversial. The utility of pharmacologic 
prophylaxis for the prevention of CVC-associated thrombosis, particularly in high risk CF individuals, deserves further study (6).

\section{SEPSIS AND SYSTEMIC INFECTION}

Bacterial sepsis is a classic example of inflammation-triggered coagulation induced by endothelial injury and tissue factor expression following an acute systemic inflammatory response, (78) leading to activation and consumption of coagulation factors and platelets, along with impaired fibrinolysis, disruption of endothelial barrier, and loss of physiologic antithrombotic factors such as thrombomodulin (79). Sepsis denotes progressively more severe host defense reactions to invading organisms with endothelial dysfunction and elevation of inflammatory markers triggering the activation of coagulation with concurrent down-regulation of anticoagulant systems and fibrinolysis (disseminated intravascular coagulation, DIC) which, in turn, contributes to increased inflammation. There is significant interplay between inflammation and coagulation in sepsis, highlighted by the procoagulant properties of the endothelium such as expression of tissue factor (TF) and VWF, activating interactions with platelets, release of procoagulant microparticles, and downregulation of TF pathway inhibitor (TFPI) and the protein $\mathrm{C} / \mathrm{S}$ anticoagulant system, inhibiting fibrinolysis. The coagulation response serves to isolate the invasive organism, but some bacteria have adapted to this and can use the coagulation response to hide from immune attack $(12,46,80)$.

As mentioned above regarding B. cepacia specifically imparting elevated VTE risk in CF patients, certain clinical variables and bacterial virulence factors are associated with VTE in Staphylococcus aureus bacteremia (Methicillinresistance, CRP $>20 \mathrm{mg} / \mathrm{dL}$, and hemoglobin nadir $</=$ $9 \mathrm{~g} / \mathrm{dL}$, though it may not always be clear whether anemia was an additional factor in the development of thrombus or is a marker of more severe disease) (11). These findings were comparable to those from another study of 70 children with osteomyelitis where in an elevated CRP was associated with increased VTE risk (81). Furthermore, a study of over 10,000 subjects in the Atherosclerosis Risk in Communities (ARIC) study, CRP above the 90th percentile was associated with a $76 \%$ increase in risk of VTE versus lower percentiles (24). A recent study of 39,831 patients who underwent colorectal surgery demonstrated a $2.4 \%$ incidence of VTE, associated with urinary tract infections, pneumonia, organ space surgical site infection, or deep surgical site infection (3).

\section{REFERENCES}

1. Agnelli G. Prevention of venous thromboembolism in surgical patients. Circulation (2004) 110:IV4-12. doi: 10.1161/01.CIR.0000150639.98514.6c

2. Gould MK, Garcia DA, Wren SM, Karanicolas PJ, Arcelus JI, Heit JA, et al. Prevention of VTE in nonorthopedic surgical patients:

\section{SYSTEMIC LUPUS ERYTHEMATOSUS}

In general, inflammatory rheumatologic diseases (lupus, Sjogren's syndrome, inflammatory myositis, and systemic sclerosis) are associated with high VTE rates-more than three times higher than in the general population (22). In particular, patients with systemic lupus erythematosus (SLE) are at significantly increased risk for premature atherosclerosis and thrombosis not only due to direct effects of chronic systemic inflammation but also to the additional risk imparted by antiphospholipid antibodies (21). This acquired, multi-organ, autoimmune disease itself is an independent risk factor for both arterial and venous thrombotic events, particularly in those with the antiphospholipid syndrome. Myriad factors influence atherosclerosis and cardiovascular disease in SLE patients, including those related to the disease itself (INF-alpha, TNF-alpha, MCP-1, cystatin C, kidney disease, overexpression of ICAM/VCAM/VEGF/VWF, NETs, elevations of interleukins $6 / 12 / 17 / 18$, and other acute phase reactants) and to the medications used to treat it (corticosteroids, antimalarials, mycophenolate mofetil, HMG-CoA reductase inhibitors, and non-steroidal anti-inflammatories) (20). Individuals with SLE have been shown to have decreased DNasel activity in their serum, which decreases NET degradation, and may contribute to thrombus formation (47). Activation of the innate immune system as evidenced by the elevation of TNF-alpha and the interleukins described above increases the risk of VTE even after adjustment for CRP (62). Polymorphisms in genes encoding factor VIII, Interleukin-1 $\beta$, and interleukin10 have been shown to modulate the risk of idiopathic VTE (82).

The lupus nephritis and autoimmune thrombocytopenia found in some of these patients also complicate the anticoagulant strategies and their standardization, but consistent APLA screening, renal evaluation/management, and use of hydroxycholorquine may decrease thrombotic risk or at least disease-related morbidity/mortality (19).

\section{CONCLUSION}

Clinical observations and mounting laboratory evidence support a complex interplay between inflammation, innate immunity, and the coagulation system. As more is understood about these interactions, novel preventive and treatment modalities for thrombosis will likely become available.

\section{AUTHOR CONTRIBUTIONS}

$\mathrm{BB}$ and SC contributed equally to the preliminary literature review, as well as the writing and revision of the manuscript.
Antithrombotic Therapy and Prevention of Thrombosis, 9th ed: American College of Chest physicians evidence-based clinical practice guidelines. Chest (2012) 141:e227S-77S. doi: 10.1378/chest.11 $-2297$

3. Monn MF, Hui X, Lau BD, Streiff M, Haut ER, Wick EC, et al. Infection and venous thromboembolism in patients undergoing colorectal 
surgery: what is the relationship? Dis Colon Rectum (2014) 57:497-505. doi: 10.1097/DCR.0000000000000054

4. Olson NC, Cushman M, Lutsey PL, McClure LA, Judd S, Tracy RP, et al. Inflammation markers and incident venous thromboembolism: the REasons for Geographic And Racial Differences in Stroke (REGARDS) cohort. $J$ Thromb Haemost. (2014) 12:1993-2001. doi: 10.1111/jth.12742

5. Munck A, Kheniche A, Alberti C, Hubert D, Martine RG, NoveJosserand $\mathrm{R}$, et al. Central venous thrombosis and thrombophilia in cystic fibrosis: a prospective study. J Cyst Fibros. (2015) 14:97-103. doi: 10.1016/j.jcf.2014.05.015

6. Takemoto CM. Venous thromboembolism in cystic fibrosis. Pediatr Pulmonol. (2012) 47:105-12. doi: 10.1002/ppul.21566

7. Knight-Perry J, Branchford BR, Thornhill D, Martiniano SL, Sagel SD, Wang M. Venous thromboembolism in children with cystic fibrosis: retrospective incidence and intrapopulation risk factors. Thromb Res. (2017) 158:161-6. doi: 10.1016/j.thromres.2017.08.022

8. Levi M, Schultz M, van der Poll T. Sepsis and thrombosis. Semin Thromb Hemost. (2013) 39:559-66. doi: 10.1055/s-0033-1343894

9. Levi M, and van der Poll T. Endothelial injury in sepsis. Intensive Care Med. (2013) 39:1839-42. doi: 10.1007/s00134-013-3054-1

10. Schouten $M$, Wiersinga WJ, Levi $M$, van der Poll $T$. Inflammation, endothelium, and coagulation in sepsis. J Leukoc Biol. (2008) 83:536-45. doi: $10.1189 / \mathrm{jlb} .0607373$

11. Carpenter SL, Goldman J, Sherman AK, Jeremiah Bell J, Selveraju S, Newland JG, et al. Clinical variables and Staphylococcus aureus virulence factors associated with venous thromboembolism in children. Thromb Res. (2016) 138:69-73. doi: 10.1016/j.thromres.2015.11.029

12. Levi M, Keller TT, van Gorp E, ten Cate H. Infection and inflammation and the coagulation system. Cardiovasc Res. (2003) 60:26-39. doi: 10.1016/S0008-6363(02)00857-X

13. Journeycake JM, Buchanan GR. Catheter-related deep venous thrombosis and other catheter complications in children with cancer. J Clin Oncol. (2006) 24:4575-80. doi: 10.1200/JCO.2005.05.5343

14. Kuhle S, Spavor M, Massicotte P, Halton J, Cherrick I, Dix D, et al. Prevalence of post-thrombotic syndrome following asymptomatic thrombosis in survivors of acute lymphoblastic leukemia. J Thromb Haemost. (2008) 6:589-94. doi: 10.1111/j.1538-7836.2008.02901.x

15. Walker AJ, Grainge MJ, Card TR, West J, Ranta S, Ludvigsson JF. Venous thromboembolism in children with cancer - a population-based cohort study. Thromb Res. (2014) 133:340-4. doi: 10.1016/j.thromres.2013.12.021

16. Giannotta M, Tapete G, Emmi G, Silvestri E, Milla M. Thrombosis in inflammatory bowel diseases: what's the link? Thromb J. (2015) 13:14. doi: 10.1186/s12959-015-0044-2

17. Koutroumpakis EI, Tsiolakidou G, Koutroubakis IE. Risk of venous thromboembolism in patients with inflammatory bowel disease. Semin Thromb Hemost. (2013) 39:461-8. doi: 10.1055/s-0033-1343886

18. Murthy SK, Nguyen GC. Venous thromboembolism in inflammatory bowel disease: an epidemiological review. Am J Gastroenterol. (2011) 106:713-8. doi: 10.1038 /ajg.2011.53

19. Al-Homood IA. Thrombosis in systemic lupus erythematosus: a review article. ISRN Rheumatol. (2012) 2012:428269. doi: 10.5402/2012/4 28269

20. Bazzan M, Vaccarino A, Marletto F. Systemic lupus erythematosus and thrombosis. Thromb J. (2015) 16:13. doi: 10.1186/s12959-015-0043-3

21. Erkan D. Lupus and thrombosis. J Rheumatol. (2006) 33:1715-7.

22. Lee JJ, Pope JE. A meta-analysis of the risk of venous thromboembolism in inflammatory rheumatic diseases. Arthritis Res Ther. (2014) 16:435. doi: 10.1186/s13075-014-0435-y

23. Saghazadeh A, Hafizi S, Rezaei N. Inflammation in venous thromboembolism: Cause or consequence? Int Immunopharmacol. (2015) 28:655-65. doi: 10.1016/j.intimp.2015.07.044

24. Folsom AR, Lutsey PL, Astor BC, Cushman M. C-reactive protein and venous thromboembolism. A prospective investigation in the ARIC cohort. Thromb Haemost. (2009) 102:615-9. doi: 10.1160/TH09-04-0274

25. Gao Q, Zhang P, Wang W, Ma H, Tong Y, Zhang J, et al. The correlation analysis of tumor necrosis factor-alpha-308G/A polymorphism and venous thromboembolism risk: a meta-analysis. Phlebology (2016) 31:625-31. doi: $10.1177 / 0268355515607405$
26. Mahemuti A, Abudureheman K, Aihemaiti X, Hu XM, Xia YN, Tang BP, et al. Association of interleukin-6 and C-reactive protein genetic polymorphisms levels with venous thromboembolism. Chin Med J. (2012) 125:3997-4002. doi: 10.3760/cma.j.issn.0366-6999.2012.22.016

27. Matos MF, Lourenco DM, Orikaza CM, Bajerl JA, Noguti MA, Morelli VM. The role of IL-6, IL-8 and MCP-1 and their promoter polymorphisms IL-6-174GC, IL-8-251AT and MCP-1-2518AG in the risk of venous thromboembolism: a case-control study. Thromb Res. (2011) 128:216-20. doi: 10.1016/j.thromres.2011.04.016

28. Poredos P, Jezovnik MK. The role of inflammation in venous thromboembolism and the link between arterial and venous thrombosis. Int Angiol. (2007) 26:306-11.

29. Long AT, Kenne E, Jung R, Fuchs TA, Renne T. Contact system revisited: an interface between inflammation, coagulation, and innate immunity. J Thromb Haemost. (2016) 14:427-37. doi: 10.1111/jth.13235

30. van Montfoort ML, Meijers JC. Recent insights into the role of the contact pathway in thrombo-inflammatory disorders. Hematol Am Soc Hematol Educ Program (2014) 2014:60-5. doi: 10.1182/asheducation-2014.1.60

31. Wu Y. Contact pathway of coagulation and inflammation. Thromb J. (2015) 13:17. doi: 10.1186/s12959-015-0048-y

32. Kyrle PA, Eichinger S. Deep vein thrombosis. Lancet (2005) 365:1163-74. doi: 10.1016/S0140-6736(05)71880-8

33. Wakefield TW, Myers DD, Henke PK. Mechanisms of venous thrombosis and resolution. Arterioscler Thromb Vasc Biol. (2008) 28:387-91. doi: 10.1161/ATVBAHA.108.162289

34. Date K, Ettelaie C, Maraveyas A. Tissue fator-bearing microparticles and inflammation: a potential mechanism for the development of venous thromboembolism in cancer. J Thromb Haemost. (2017)15:2289-99. doi: $10.1111 /$ jth. 13871

35. Manly DA, Boles J, Mackman N. Role of tissue factor in venous thrombosis. Аnnu Rev Physiol. (2011) 73:515-25. doi: 10.1146/annurev-physiol-042210-121137

36. Kroegel C, Reissig A. Principle mechanisms underlying venous thromboembolism: epidemiology, risk factors, pathophysiology and pathogenesis. Respiration (2003) 70:7-30. doi: 10.1159/000068427

37. Meissner MH, Wakefield TW, Ascher E, Caprini JA, Comerota AJ, Eklof B, et al. Acute venous disease: venous thrombosis and venous trauma. J Vasc Surg. (2007) 46(Suppl. S):25S-53S. doi: 10.1016/j.jvs.2007.08.037

38. Bernard J, Yi ES. Pulmonary thromboendarterectomy: a clinicopathologic study of 200 consecutive pulmonary thromboendarterectomy cases in one institution. Hum Pathol. (2007) 38:871-7. doi: 10.1016/j.humpath.2006.11.017

39. Cheng KB, Wang LM, Gao HJ, Hu Y. An study on screening the gene clusters associated with pulmonary embolism-deep venous thrombosis by oligo microarray. Zhonghua Yi Xue Za Zhi (2007) 87:2420-2.

40. Piazza G. Beyond Virchow's Triad: does cardiovascular inflammation explain the recurrent nature of venous thromboembolism? Vasc Med. (2015) 20:1024. doi: $10.1177 / 1358863$ X14568706

41. Choi SH, Smith SA, Morrissey JH. Polyphosphate accelerates factor $\mathrm{V}$ activation by factor XIa. Thromb Haemost. (2015) 113:599-604. doi: 10.1160/TH14-06-0515

42. Docampo R. Polyphosphate: a target for thrombosis attenuation. Blood (2014) 124:3177-8. doi: 10.1182/blood-2014-09-601641

43. Morrissey JH. Polyphosphate: a link between platelets, coagulation and inflammation. Int $J$ Hematol. (2012) 95:346-52. doi: 10.1007/s12185-012-1054-5

44. Travers RJ, Smith SA, Morrissey JH. Polyphosphate, platelets, and coagulation. Int $J$ Lab Hematol. (2015) 37(Suppl. 1):31-5. doi: $10.1111 /$ ijlh.12349

45. Xu J, Lupu F, Esmon CT. Inflammation, innate immunity and blood coagulation. Hamostaseologie (2010) 30:5-6, 8-9. doi: 10.1055/s-0037-1617146

46. Esmon CT, Xu J, Lupu F. Innate immunity and coagulation. J Thromb Haemost. (2011) 9:(Suppl. 1)182-8. doi: 10.1111/j.1538-7836.2011.04323.x

47. Fuchs TA, Brill A, Wagner DD. Neutrophil extracellular trap (NET) impact on deep vein thrombosis. Arterioscler Thromb Vasc Biol. (2012) 32:1777-83. doi: 10.1161/ATVBAHA.111.242859

48. Engelmann B, Massberg S. Thrombosis as an intravascular effector of innate immunity. Nat Rev Immunol. (2013) 13:34-45. doi: 10.1038/nri3345 
49. Semple JW, Freedman J. Platelets and innate immunity. Cell Mol Life Sci. (2010) 67:499-511. doi: 10.1007/s00018-009-0205-1

50. Vieira-de-Abreu A, Campbell RA, Weyrich AS, Zimmerman GA. Platelets: versatile effector cells in hemostasis, inflammation, and the immune continuum. Semin Immunopathol. (2012) 34:5-30. doi: 10.1007/s00281-011-0286-4

51. Schmidt M, Christiansen CF, Horvath-Puho E, Glynn RJ, Rothman KJ, Sorensen HT. Non-steroidal anti-inflammatory drug use and risk of venous thromboembolism. J Thromb Haemost. (2011) 9:1326-33. doi: 10.1111/j.1538-7836.2011.04354.x

52. Ungprasert P, Srivali N, Wijarnpreecha K, Charoenpong P, Knight EL. Nonsteroidal anti-inflammatory drugs and risk of venous thromboembolism: a systematic review and meta-analysis. Rheumatology (2015) 54:736-42. doi: 10.1093/rheumatology/keu408

53. Johannesdottir SA, Horvath-Puho E, Dekkers OM, Cannegieter SC, Jorgensen JO, Ehrenstein V, et al. Use of glucocorticoids and risk of venous thromboembolism: a nationwide population-based case-control study. JAMA Intern Med. (2013) 173:743-52. doi: 10.1001/jamainternmed.2013.122

54. Kantar RS, Haddad AG, Tamim H, Jamali F, Taher AT. Venous thromboembolism and preoperative steroid use: analysis of the NSQIP database to evaluate risk in surgical patients. Eur J Intern Med. (2015) 26:528-33. doi: 10.1016/j.ejim.2015.06.005

55. Koh TJ, DiPietro LA. Inflammation and wound healing: the role of the macrophage. Expert Rev Mol Med. (2011) 13:e23. doi: $10.1017 / S 1462399411001943$

56. Ross R, Odland G. Human wound repair. II. Inflammatory cells, epithelialmesenchymal interrelations, and fibrogenesis. J Cell Biol. (1968) 39:152-68. doi: $10.1083 /$ jcb.39.1.152

57. Artuc M, Hermes B, Steckelings UM, Grutzkau A, Henz BM. Mast cells and their mediators in cutaneous wound healing-active participants or innocent bystanders?. Exp Dermatol. (1999) 8:1-16. doi: 10.1111/j.1600-0625.1999.tb00342.x

58. Barbul A, Breslin RJ, Woodyard JP, Wasserkrug HL, Efron G. The effect of in vivo $\mathrm{T}$ helper and $\mathrm{T}$ suppressor lymphocyte depletion on wound healing. Ann Surg. (1989) 209:479-83. doi: 10.1097/00000658-19890400000015

59. Barrientos S, Stojadinovic O, Golinko MS, Brem H, Tomic-Canic M. Growth factors and cytokines in wound healing. Wound Repair Regen. (2008) 16:585601. doi: 10.1111/j.1524-475X.2008.00410.x

60. Diegelmann RF, Evans MC. Wound healing: an overview of acute, fibrotic and delayed healing. Front Biosci. (2004) 9:283-9. doi: 10.2741/1184

61. Wang Y, Golden JB, Fritz Y, Zhang X, Diaconu D, Camhi MI, et al. Interleukin 6 regulates psoriasiform inflammation-associated thrombosis. JCI Insight (2016) 1:e89384. doi: 10.1172/jci.insight.89384

62. Reitsma PH, Rosendaal FR. Activation of innate immunity in patients with venous thrombosis: the Leiden Thrombophilia Study. J Thromb Haemost. (2004) 2:619-22. doi: 10.1111/j.1538-7836.2004.00689.x

63. Savchenko AS, Martinod K, Seidman MA, Wong SL, Borissoff JI, Piazza G, et al. Neutrophil extracellular traps form predominantly during the organizing stage of human venous thromboembolism development. J Thromb Haemost. (2014) 12:860-70. doi: 10.1111/jth.12571

64. Myers DD Jr., Rectenwald JE, Bedard PW, Kaila N, Shaw GD, Schaub RG, et al. Decreased venous thrombosis with an oral inhibitor of P selectin. J Vasc Surg. (2005) 42:329-36. doi: 10.1016/j.jvs.2005.04.045

65. Myers DDJr., Henke PK, Wrobleski SK, Hawley AE, Farris DM, Chapman AM, etal. P-selectin inhibition enhances thrombus resolution and decreases vein wall fibrosis in a rat model. J Vasc Surg. (2002) 36:928-38. doi: $10.1067 /$ mva.2002.128636

66. Culmer DL, Dunbar ML, Hawley AE, Sood S, Sigler RE, Henke PK, et al. E-selectin inhibition with GMI-1271 decreases venous thrombosis without profoundly affecting tail vein bleeding in a mouse model. Thromb Haemost. (2017) 117:1171-81. doi: 10.1160/TH16-04-0323

67. Murch SH, Lamkin VA, Savage MO, Walker-Smith JA, MacDonald TT. Serum concentrations of tumour necrosis factor alpha in childhood chronic inflammatory bowel disease. Gut (1991) 32:913-7. doi: 10.1136/gut.32.8.913

68. Dionne S, Hiscott J, D'Agata I, Duhaime A, Seidman EG. Quantitative PCR analysis of TNF-alpha and IL-1 beta mRNA levels in pediatric IBD mucosal biopsies. Dig Dis Sci. (1997) 42:1557-66. doi: 10.1023/A:1018895500721

69. Matsuda R, Koide T, Tokoro C, Yamamoto T, Godai T, Morohashi T, et al. Quantitive cytokine mRNA expression profiles in the colonic mucosa of patients with steroid naive ulcerative colitis during active and quiescent disease. Inflamm Bowel Dis. (2009) 15:328-34. doi: 10.1002/ibd.20759

70. Lentz SR. Thrombosis in the setting of obesity or inflammatory bowel disease. Blood (2016) 128:2388-94. doi: 10.1182/blood-2016-05-716720

71. Samad F, Ruf W. Inflammation, obesity, and thrombosis. Blood (2013) 122:3415-22. doi: 10.1182/blood-2013-05-427708

72. Blokhin IO, Lentz SR. Mechanisms of thrombosis in obesity. Curr Opin Hematol. (2013) 20:437-44. doi: 10.1097/MOH.0b013e3283634443

73. Burk CD, Miller L, Handler SD, Cohen AR. Preoperative history and coagulation screening in children undergoing tonsillectomy. Pediatrics (1992) 89:691-5. doi: 10.1097/00132586-199212000-00035

74. Currimbhoy Z. Transitory anticoagulants in healthy children. Am J Pediatr Hematol Oncol. (1984) 6:210-2. doi: 10.1097/00043426-198406020-00017

75. O'Sullivan BP, Michelson AD. The inflammatory role of platelets in cystic fibrosis. Am J Respir Crit Care Med. (2006) 173:483-90. doi: 10.1164/rccm.200508-1243PP

76. Raffini LJ, Raybagkar D, Blumenstein MS, Rubenstein RC, Manno CS. Cystic fibrosis as a risk factor for recurrent venous thrombosis at a pediatric tertiary care hospital. J Pediatr. (2006) 148:659-64. doi: 10.1016/j.jpeds.2005.11.032

77. Afshar K, Benitez DS, Purush R. Catheter-Associated Venous Thromboembolism in Patients with Cystic Fibrosis. J Pulmon Resp Med. (2013) 3:143. doi:10.4172/2161-105X.1000143

78. Levi M, Poll T. Coagulation in patients with severe sepsis. Semin Thromb Hemost. (2015) 41:9-15. doi: 10.1055/s-0034-1398376

79. Foley JH, Conway EM. Cross talk pathways between coagulation and inflammation. Circ Res. (2016) 118:1392-408. doi: 10.1161/CIRCRESAHA.116.306853

80. Kastrup CJ, Boedicker JQ, Pomerantsev AP, Moayeri M, Bian Y, Pompano RR, et al. Spatial localization of bacteria controls coagulation of human blood by 'quorum acting'. Nat. Chem. Biol. (2008) 4:742-50. doi: 10.1038/nchembio.124

81. Bouchoucha S, Benghachame F, Trifa M, Saied W, Douira W, Nessib $\mathrm{MN}$, etal. Deep venous thrombosis associated with acute hematogenous osteomyelitis in children. Orthop Traumatol Surg Res. (2010) 96:890-3. doi: 10.1016/j.otsr.2010.05.006

82. Zee RY, Glynn RJ, Cheng S, Steiner L, Rose L, Ridker PM. An evaluation of candidate genes of inflammation and thrombosis in relation to the risk of venous thromboembolism: The Women's Genome Health Study. Circ Cardiovasc Genet. (2009) 2:57-62. doi: 10.1161/CIRCGENETICS.108.801969

Conflict of Interest Statement: The authors declare that the research was conducted in the absence of any commercial or financial relationships that could be construed as a potential conflict of interest.

Copyright (c) 2018 Branchford and Carpenter. This is an open-access article distributed under the terms of the Creative Commons Attribution License (CC $B Y)$. The use, distribution or reproduction in other forums is permitted, provided the original author(s) and the copyright owner are credited and that the original publication in this journal is cited, in accordance with accepted academic practice. No use, distribution or reproduction is permitted which does not comply with these terms. 